\title{
A representação da vaquejada na Literatura de Cordel
}

\author{
La representación de la vaquillada en la Literatura de Cordel \\ The representation of the vaquejada in Cordel Literature
}

Paulo Gracino da Silva ${ }^{1}$

\begin{abstract}
Resumo
A representação da vaquejada na Literatura de Cordel é exposta neste artigo, a partir da análise d 'A história do boi misterioso, dialogando com outras obras e poetas cordelistas e os estudos de Cascudo (1984) e Luciano (2012), no sentido de delinear a trajetória histórica destas duas culturas em meio às transformações da sociedade, desde o início do século XX até os dias atuais. Está fundamentada nos pressupostos da História Cultural, tendo como base teórica Burke (2008) e Chartier (2002), enquanto que para a compreensão do valor da literatura e sua função social, Todorov (2009) foi o norteador dos argumentos. Concluímos que nesta caminhada o Cordel e a vaquejada se reajustam e se reinventam para se manterem vivas enquanto tradições, com o poeta se apropriando dos elementos essenciais à prática da vaquejada - cavalo, boi e vaqueiro - para valorizar suas narrativas e ao mesmo tempo enaltecer e propagandear a cultura da vaquejada.
\end{abstract}

Palavras-chave: Literatura de Cordel; Representação; Vaquejada.

\section{Resumen}

La representación de la vaquillada en la Literatura de Cordel es expuesta en este artículo, a partir del análisis de La historia del buey misterioso, dialogando con otras obras y poetas cordelistas y los estudios de Cascudo (1984) y Luciano (2012), en el sentido de delinear la trayectoria histórica de estas dos culturas en medio de las transformaciones de la sociedad, desde el inicio del siglo XX hasta los días actuales. En el caso de La historia Cultural, teniendo como base teórica Burke (2008) y Chartier (2002), mientras que para la comprensión del valor de la literatura y su función social, Todorov (2009) fue el orientador de los argumentos. Concluimos que en esta caminata el Cordel y la vaquillada se reajustan y se reinventan para mantenerse vivas como tradiciones, con el poeta apropiándose de los elementos esenciales a la práctica de la vaquillada - caballo, buey y vaquero para valorar sus narrativas y al mismo tiempo enaltecer y propagar la cultura de la vaquillada.

Palabras clave: Literatura de Cordel; Representación; vaquillada.

\begin{abstract}
The representation of the vaquejada in the Literature of Cordel is exposed in this article, from the analysis of The history of the mysterious ox, dialoguing with other cordelistas works and poets and the studies of Cascudo (1984) and Luciano (2012), in the sense of delineating the historical trajectory of these two cultures in the midst of the transformations of society, from the beginning of the twentieth century to the present day. It is based on the assumptions of Cultural History, based on Burke (2008) and Chartier (2002), while for understanding the value of literature and its social function, Todorov (2009) was the guiding force behind the arguments. We conclude that in this trek the Cordel and the vaquejada are readjusted and reinvented to keep alive as traditions, with the poet appropriating the essential elements to the practice of the vaquejada - horse, ox and cowboy - to valorize their narratives and at the same time to extol and to propagate the vaquejada culture.
\end{abstract}

Keywords: Cordel literature; Representation; Vaquejada.

\footnotetext{
${ }^{1}$ Possui graduação em História (UEPB) e Serviço Social (UNIP), mestrando do Programa de Pós-Graduação em História pela UFPB, sendo bolsista da CAPES. E-mail: pgracino@ gmail.com.
} 


\section{Tradições nordestinas}

Quem procurar conhecer as tradições do universo nordestino dificilmente irá deixar de interagir com a Literatura de Cordel e com a vaquejada, principalmente quando os estudos forem fundamentados nos princípios da História Cultural. Digo isto porque "o terreno comum dos historiadores culturais pode ser descrito como a preocupação com o símbolo e suas interpretações" (BURKE, 2008, p. 10), e estes dois elementos de origem nordestina simbolizam muito bem a cultura do seu povo, tendo ambos, uma correlação histórica, a qual é abordada neste texto.

Como pretendemos apresentar a representação da vaquejada na Literatura de Cordel e suas lutas constantes pela sobrevivência em meio às transformações socioculturais, do início do século XX ao início do XXI, estamos cientes de que o nosso interesse pelo tema está em conformidade com a metodologia de pesquisa da História Cultural tanto na percepção de Peter Burke (2008, p. 8), que afirma que o historiador cultural deve direcionar suas pesquisas aos "valores defendidos por grupos particulares em locais e períodos específicos", quanto na de Roger Chartier (2002, p. 16-7), que defende que "a história cultural, tal como a entendemos, tem por principal objecto identificar o modo como em diferentes lugares e momentos uma determinada realidade social é construída, pensada, dada a ler". Tudo isso significa dizer que esta pesquisa se enquadra nas perspectivas da História Cultural sem se distanciar dos fundamentos básicos do ofício do historiador, que, para Bloch (2012, p. 54), busca "capturar" a história dos homens através do tempo e aquela que "não conseguir isso será apenas, no máximo, um serviçal da erudição. Já o bom historiador se parece com o ogro da lenda. Onde fareja carne humana, sabe que ali está a sua caça".

Tomando a Literatura de Cordel como fonte histórica é possível imaginar seu valor e sua riqueza a respeito dos conhecimentos relacionados à prática da vaquejada. Mas abordando este modelo literário como fonte de ensinamento, ou como fonte de alfabetização e letramento literário (MARINHO e PINHEIRO, 2012) é possível compreender o quanto esta poesia foi e é útil ao processo educacional brasileiro, sobretudo na região nordestina, levando aos leitores (além das críticas, lendas, mitos, notícias) a representação da vaquejada e suas tradições, como está exposta neste artigo.

Com base nestas informações é que explicamos a importância de analisar $A$ história do boi misterioso - Cordel de Leandro Gomes de Barros, escrito em 222 estrofes de sextilhas de sete sílabas poéticas, no provável ano de 1912 (LUCIANO, 2012) - como objeto central da pesquisa, pois entendemos que este folheto é considerado um clássico deste gênero literário, 
perdurando por mais de um século como leitura "obrigatória" entre os apreciadores da poesia rimada e metrificada do Cordel brasileiro. Isto se justifica ao identificarmos a presença desta obra nas diversas coletâneas destinadas às salas de aula, nos inúmeros arquivos relacionados ao Cordel, ou nos milhares de folhetos impressos pelo mundo afora. E mais, o quanto esta obra foi lida, relida e ouvida nestes mais de cem anos de existência.

Para fortalecer a análise d'A história do boi misterioso foi feita a abordagem de outras obras de Leandro Gomes de Barros e de outros poetas cordelistas, enfocando a presença do vaqueiro, do boi e do cavalo (através do tempo), por serem os três elementos indispensáveis à prática da vaquejada nordestina, desde sua fase embrionária nas apartações até os dias atuais.

Esta análise interdisciplinar (literária e historiográfica) tem como diretriz os estudos de Cascudo (1984), que mostra as primeiras preocupações acerca das transformações socioculturais e dos "perigos" que a modernidade impõe às tradições, no contexto em que as apartações criavam forma de vaquejada e os indícios apontavam para o surgimento do Cordel brasileiro, como o conhecemos. Neste sentido, Luciano (2012) norteia os conhecimentos em torno da Literatura de Cordel e aponta caminhos que levam aos nossos pressupostos de que Cordel e vaquejada parecem caminhar lado a lado desde o início do século XX até os dias atuais, reconstruindo-se e se reinventado para sobreviver enquanto tradições e práticas.

Na primeira parte deste artigo é feita uma discussão sobre a correlação existente entres estas duas culturas no período abordado, analisando os estudos de Cascudo (1984) e de Luciano (2012) com relação à vaquejada e ao Cordel, respectivamente, e as obras de outros poetas que têm como tema a vaquejada, de forma direta e ou indireta (cronologicamente).

$\mathrm{Na}$ segunda parte está exposto o estudo sobre as obras de outros poetas contemporâneos de Leandro Gomes de Barros - Silvino Pirauá, Francisco das Chagas Batista e João Martins de Ataíde - que também abordaram a vaquejada em seus textos e contextos, partindo dos estudos de Luciano (2012) que os indicam (ao lado de Leandro) como os responsáveis pela consolidação do Cordel no cenário literário. São apresentados também os estudos feitos noutras obras de Leandro, mostrando que a vaquejada está presente na sua escrita para além d'A história do boi misterioso, obra esta, apontada como a que imortalizou a presença do boi na Literatura de Cordel (LUCIANO, 2012).

A história do lendário barbatão narrada por Leandro Gomes de Barros é analisada na terceira parte deste texto. A análise da obra se faz de forma minuciosa, mas não definitiva, tomando por base os fundamentos da História Cultural, relacionando-os com os conhecimentos legados de Cascudo (1984), de uma maneira que os leitores percebam a presença dos métodos e práticas que norteiam os conhecimentos produzidos nas academias. 
Por último vêm as considerações finais acerca da representação da vaquejada na Literatura de Cordel brasileira, dando ênfase à contribuição de um para o outro e de ambos para a representação da cultura nordestina, onde se vê a vaquejada servindo de fonte de inspiração para o Cordel e o Cordel servindo de meio de divulgação para a vaquejada.

\section{Cordel e vaquejada: mais de cem anos entre práticas e resistências}

Existem duas culturas nordestinas que estão presentes lado a lado há mais de um século e se relacionam quase que mutuamente ao longo desse tempo, são a vaquejada e a Literatura de Cordel brasileira. Nesta caminhada, a vaquejada fornece personagens e cenários ideais à construção das narrativas de Cordel, enriquecendo ainda mais o poder criativo dos poetas cordelistas. Muitos estudos registram esta marcha de luta pela sobrevivência em meios às transformações sociais do país e do mundo, demonstrando que, além desta união correlativa, elas representam a identidade cultural de um povo, de uma região.

Vê-se atualmente diversos movimentos contrários à prática da vaquejada em todo o país, como também é possível perceber o empenho de muitos amantes deste esporte lutando para manter vivas as tradições que foram construídas desde a segunda metade do século XIX, nas terras nordestinas. Percebe-se, com isso, que o que existe na atualidade são confrontos de culturas que batalham dentro de um mesmo espaço pela sobrevivência. Esta é uma síntese da trajetória da vaquejada que luta em pleno século XXI para sobreviver diante de um mundo mais urbanizado, mais modernizado e cada vez mais regrado pelo desenvolvimento tecnológico. Seria a luta pela sobrevivência de uma tradição de origem rural, em meio a uma sociedade urbana e "líquida" (tomando emprestado o termo de Zygmunt Bauman) que não tem sequer características para construir tradições, quanto mais para manter tradições que perduram há várias gerações. Ou seja, além das condições socioculturais não favoreceram às tradições, ainda surgem outras culturas que se colocam contrárias às existentes, que é o caso dos grupos defensores dos animais, contemporâneos da prática da vaquejada. Mesmo assim, a vaquejada, por meio de seus defensores e idealizadores, busca novas alternativas para se adequar aos tempos atuais, criando novas regras, novos formatos, novas condições e até leis que viabilizem sua prática.

Paralelo a isso, a Literatura de Cordel brasileira também trilhou por caminhos tortuosos e enfrentou várias situações que pareciam determinar o seu extermínio. Surgida por volta do final do século XIX, foi o grande instrumento de informação e entretenimento das populações de massa, ou das classes menos favorecidas intelectualmente (CAMPOS, 1959), 
reinando quase que absoluta (no meio dessa camada social) até o fim da primeira metade do século XX. Mas com o surgimento da televisão brasileira, que tomara o lugar do leitor do Cordel nas rodas familiares e encontros de leituras entre vizinhos, acreditou-se que as histórias escritas em rima e métrica pelos poetas “populares” estariam fadadas à extinção. Pensou-se nesta possibilidade até quando os cordéis passaram a serem objetos de estudos nas academias e foram levados às salas de aula do ensino básico, uma vez que até então as poesias “ditas populares" eram muito produzidas e pouco estudadas e/ou pesquisadas. Além do mais, com o processo de desenvolvimento industrial brasileiro, o Cordel embarcara na migração do povo nordestino para o Sul e o Sudeste do país ${ }^{2}$, ganhando novos espaços geográficos e expandindo-se enquanto tradição cultural. Vê-se, então, o ressurgimento de uma tradição em meio às transformações geográficas, sociais, culturais e tecnológicas, buscando seu espaço de acordo com as condições impostas pelo contexto. O Cordel brasileiro, assim como fez/faz a vaquejada, busca novas saídas para não correr o risco de desaparecer, se adequando às condições contemporâneas e encontrando outros espaços para se manter viva enquanto prática e tradição.

Chamo a atenção para estes dois elementos da nossa cultura por saber da importância de ambos para a formação identitária da sociedade nordestina. E mais, pelo fato de que eles sempre estiveram relacionados, caminhando juntos nesta luta pela sobrevivência ao longo do tempo. Pode-se afirmar que vaquejada e Cordel estiveram sempre lado a lado, ou, melhor dizendo, que pelo menos o Cordel surgiu coladinho com a prática da vaquejada. Ao abordamos os estudos de Cascudo (1984), um especialista da cultura popular nordestina, podemos perceber esta relação entre as festas de "apartação" e os poetas cantadores, e em seguida com os cordelistas. Ou quando buscamos os conhecimentos do doutor em ciência da literatura, Aderaldo Luciano (2012), que faz algumas observações acerca da nacionalidade do Cordel nordestino, apontando algumas características estruturais que o diferem da cantoria, também identificamos a ligação temática entre cantadores e cordelistas, principalmente quando o assunto são os bois lendários, personagens típicos das apartações do gado no sertão do Nordeste do Brasil.

Cascudo (1984), na apresentação da sua obra Vaqueiros e Cantadores, discorre sobre esta ligação entre poesia popular e vaquejada, mas destaca inicialmente algumas transformações que sofrera o sertão das primeiras décadas do século XX. Aquelas

\footnotetext{
${ }^{2}$ Santos (2010) em seus estudos sobre a literatura de Cordel e a migração nordestina fez um artigo acerca da produção cordelística no Rio de Janeiro e São Paulo, no período entre 1950 e 1980, por poetas nordestinos radicados nestes estados.
} 
transformações ocasionavam mudanças culturais, mudanças de hábitos, costumes e tradições que permeavam a sociedade de então, mas que tais culturas não desapareceram e foram se reinventado com o passar do tempo. Digo isto porque estamos tentando exatamente compreender e discutir as transformações socioculturais mais acentuadas que dizem respeito ao Cordel e à vaquejada em suas trajetórias históricas. Ou seja, estamos diante de discussões que abordam duas tradições que se reinventam e se fortalecem há muito tempo.

Só para justificar estas informações, vê-se que Cascudo (1984) enxergava estas transformações e também percebia as readaptações das tradições como táticas de sobrevivências. Ele descreve situações que pareciam apontar para o fim da vaquejada, à época, afirmando que:

\begin{abstract}
A transformação é sensível e diária. As estradas de rodagem aproximam o sertão do agreste. [...] Os filhos se educam nos colégios distantes. Tudo perto, pelo auto. [...] Com a "alta" do algodão e do açúcar os ex-fazendeiros mandaram fazer residências nas cidades do litoral. O caminhão matou o "comboio", lento, tranqüilo, trazendo fardos, dirigido pela "madrinha", tangido pelas cantigas dos comboieiros (CASCUDO, 1984, p.15, grifos do autor).
\end{abstract}

Apesar de vermos situações que apontam para o fim da prática da vaquejada, por volta das décadas de 1920 e 1930, no sertão nordestino (período da pesquisa de Cascudo), hoje sabemos que esta tradição se reinventou, buscou novos espaços, adaptou-se ao meio urbano, apesar de a cada instante continuar se readequando às transformações para se manter como tradição de uma nação - a nação nordestina.

Ainda com base nos estudo de Cascudo (1984), podemos compreender que a vaquejada descende das festas das "apartações" do gado no Nordeste brasileiro. Ele aponta outros festejos espalhados pelo país, mas assinala que as práticas das apartações tinham finalidades objetivas, não podendo ser equiparadas a touradas, cavalhadas, corrida de argolinha, ou outras festas relacionadas ao boi e ou ao cavalo. As apartações consistiam em recolher o gado criado nos campos (sem divisões físicas) para os currais das maiores fazendas da região, sendo no mês de inverno (geralmente junho) o período em que tais práticas se realizavam. Os vaqueiros da região se juntavam para recolher o gado, identificar e devolver ao seu dono, sendo as marcas “de 'ferro' na anca, o 'sinal' recortado na orelha, a 'letra' da ribeira" (CASCUDO, 1984, p.106 grifos do autor) os elementos que possibilitavam tais identificações. Após a corrida do gado, que habitualmente se realizava pela manhã e à tarde, segundo Cascudo, à noite é que os homens se reuniam em comemorações. Era no jantar que 
os vaqueiros se juntavam para narrar suas proezas, suas façanhas, suas glórias, ou até mesmo revelar as derrotas alheias.

Descrevi estas explicações sobre as apartações e os seus desdobramentos para mostrar que existiam outras personagens (além dos vaqueiros e fazendeiros) bastantes comuns nestes encontros, pois, “indispensavelmente havia um ou dois cantadores para 'divertir' estes jantares”, segundo Cascudo (1984, p. 107 grifo do autor). Ou seja, havia poesia nesses encontros, mesmo que não fossem com poetas cordelistas - levando em conta as considerações de Luciano (2012) acerca das diferenças entre a poesia do cordelista e a do repentista (cantador) - mas já havia esta união entre a poesia popular e a vaquejada nordestina.

Nesta relação entre poesia e vaquejada, Cascudo denuncia as mudanças que ocorrem na sociedade através do tempo, como citamos acima, e identifica nas cantorias da época a presença lendária da figura do boi, bem como os traços de mudanças nas construções poéticas cantadas. Ou seja, parecia que esta denúncia refletia o surgimento do Cordel e de um novo parceiro para os vaqueiros e vaquejadas, que perduram até os dias atuais. Cascudo quando faz menção às cantorias que exaltavam os animais, muito comum no meio, confirma que:

\footnotetext{
Muitos destes versos estão misturados com outras "gestas" modernas, confundidos e baralhados na homenagem a outro bicho. Os primitivos eram todos em quadras e, repito, a sextilha denuncia a relativa modelagem recente. Os velhíssimos romances do Boi Espácio, do Boi Barroso, do Boi Surubim, da Vaca do Burel, foram todos cantados em tom menor e eram em quadras, como a maioria dos registados em Goiás e Mato Grosso onde não se deu maior influência litorânea, modificando a versificação tradicional (CASCUDO, 1984, p.115 grifo do autor).
}

De fato, Cascudo parece ser um defensor legítimo da tradição, preocupado tanto com a vaquejada quanto com as cantorias, que se entrecruzavam em meio aos festejos da apartação. É nesta denúncia que se verifica a presença do Cordel no cotidiano da vaquejada, ou a introdução de alguns elementos da estrutura do Cordel - a sextilha - nos romances que enalteciam os animais, principalmente os que estavam envolvidos diretamente com a vaquejada, que é o exemplo do boi e da vaca, acima citados. Percebe-se, com isso, uma mistura que envolve vaquejada, vaqueiro, poeta/cantadores, poesia e transformações socioculturais. Um(a) se justapondo ao(à) outro(a), seguindo novos caminhos e buscando novos rumos para se manterem como tradições, perceptível hoje.

Enquanto Cascudo (1984) faz esta denúncia a partir do seu lugar social estabelecido pelo contexto histórico da década de 1920 e 1930, o grande pesquisador de Cordel, Aderaldo Luciano (2012), aborda esta discussão com uma visão bem mais atual, do século XXI, 
trazendo informações que corroboram os nossos pressupostos. Era o Cordel brasileiro incluindo temas que outrora fora instrumento de "diversão" dos vaqueiros nas grandes reuniões das festas das apartações do gado pelo sertão nordestino.

Parece-nos indubitável que os cantadores foram os primeiros e grandes enaltecedores do temível touro, do lendário "barbatão", nos jantares comemorativos das noites sertanejas, durante as festas de apartações. Como também nos parece aceitável a idéia de que o Cordel surgiu se utilizando de elementos indispensáveis à vaquejada. A esse respeito, Luciano (2012, p. 24) afirma a existência "desse bicho tanto na oralidade quanto na escrita", e diz que:

Apesar de se terem escritas várias história em cordel sobre o temível touro, o grande responsável por imortalizar as histórias do boi em cordel foi Leandro Gomes de Barros. Encontramos sua versão da história versada em 1912, O boi misterioso, que, assim como o próprio barbatão, também virou lenda (LUCIANO, 2012, p. 25, grifos do autor).

Para explicar melhor as palavras de Luciano (2012), devemos saber que A história do boi misterioso, considerado na atualidade como um clássico deste gênero, foi todo construído em sextilhas, por Leandro Gomes de Barros; e a sextilha é uma das modalidades mais utilizadas na Literatura de Cordel, enquanto que Leandro Gomes de Barros é considerado por muitos pesquisadores como o "pai" desta escrita poética. Ou seja, apesar das diferenças apontadas por Luciano (2012) entre a sextilha do Cordel e a dos cantadores, podemos ver a sextilha como denúncia da "relativa modelagem recente", descrita por Cascudo (1984), demonstrando que a parceria existente entre a vaquejada e os cantadores, em vez de enfraquecer com a presença da modernidade e transformações culturais, remodelara-se e ganhara mais um aliado para exaltar os feitos dos vaqueiros e dos lendários bois indomáveis.

Entende-se, com isso, que os encontros realizados durante as festas de apartação no sertão nordestino, que a princípio se serviam das habilidades dos poetas cantadores para enaltecerem as suas conquistas, naquele momento recebeu a parceria do poeta de bancada (como é conhecido o escritor de Cordel) para se expandir para além dos pátios das grandes fazendas, ultrapassando os limites da memória e da oralidade. Vê-se a sextilha do cantador se misturando à sextilha do cordelista e, nesse impulso, ganhando as feiras livres, habitando outras festas populares, outros pátios de fazendas, outros públicos e novos ares, ao ponto de adentrar às universidades a partir da segunda metade do século XX.

É evidente que este vôo alçado pela vaquejada por intermédio do Cordel, já que suas histórias foram/são lidas e relidas constantemente e em lugares variados, não se limitou apenas aos escritos de Leandro Gomes de Barros e, quanto a isso, Luciano (2012, p. 84) deixa 
pistas assinalando quatro nomes contemporâneos responsáveis pela consolidação do Cordel brasileiro: "Silvino Pirauá, Leandro Gomes de Barros, João Martins de Ataíde e Francisco das Chagas Batista”. Esta informação nos faz acreditar que estes e outros cordelistas também produziram obras relativas ao boi, ao vaqueiro ou ao cavalo, já que estes são os três elementos indispensáveis à prática da antiga apartação e da atual vaquejada. Levando em consideração que A história do boi misterioso foi escrito no ano de 1912, como indica Luciano (2012), deduzimos que o próprio Leandro Gomes de Barros tenha produzido outras histórias que referenciam a vaquejada nordestina.

Para justificar os nossos argumentos (na prática) sobre esta parceria que marca a caminhada da vaquejada e do Cordel ao longo de mais de cem anos, destacamos outros nomes, além dos quatro citados por Luciano (2012), que podem confirmar tais pressupostos. João Melquíades Ferreira da Silva (1869-1933), Gonçalo Ferreira da Silva (nascido em 1937) e Klévisson Viana (nascido em 1972) são exemplos (cronológicos) que demonstram o vaqueiro e a vaquejada como produtos essenciais à escrita do Cordel, desde o início do século $\mathrm{XX}$ até os dias atuais.

João Melquíades Ferreira da Silva foi um contemporâneo dos quatro poetas referenciados por Luciano (2012), que merece destaque pelas suas produções enaltecedoras da cultura sertaneja. Ele aborda o vaqueiro num cenário específico do sujeito valente, destemido, imortal no imaginário popular. Na Estória do valente sertanejo Zé Garcia - folheto de 40 páginas - o poeta narra o romance de um jovem que se envolve em questões amorosas, mas o destaque da narrativa está no momento em que ele resolve pegar um barbatão. O que começa abordando a questão da honra feminina, estende-se para as tradições das apartações de gado, envolve o cangaço e as desavenças perigosas e termina com uma bela história de amor. Mas o que percebemos neste Cordel é a valorização do vaqueiro e do boi lendário (animal que serve para valorizar ainda mais o vaqueiro), como podemos ler nas duas estrofes que seguem:

\footnotetext{
Disse um vaqueiro a Garcia:

Vês aquele barbatão?

É o touro Saia-branca

Pertencente ao capitão

É o fantasma dos vaqueiros

E o orgulho do sertão. (p. 7)

$[\ldots]$
}

Garcia pegou o touro

Na mão a cauda enrolou

Atirou de serra a baixo

Deu um soco e derrubou

A fama do barbatão 
Nesse dia terminou. (p. 15)

Neste folheto encontramos o cenário das festas de apartação descritas por Cascudo, mas, mesmo não sendo possível datar a primeira edição desta história, sabemos que o poeta nasceu em 1869 e faleceu em dezembro de 1933, estando no mesmo contexto histórico das pesquisas do folclorista nordestino. Ou seja, aqueles jantares comemorativos que aconteciam após a corrida dos bois, descritos por Cascudo (1984), podem ser lidos nos versos do cordelista acima citado, quando ele diz que: "Mandaram levar em carga / a carne do barbatão / em casa de Miguel Feitosa / cresceu a reunião / foram chamar os cantadores / Beira-Dágua e Mandapulão" (p. 16-7).

Gonçalo Ferreira da Silva é um poeta cearense nascido na década de 1930, que migrou para o Rio de Janeiro na década de 1950, levando consigo a veia poética (www.casruibarbosa. gov.br). Mesmo só começando a produzir histórias em Cordel em 1978, período de migração da população nordestina para a cidade e grandes centros com mais intensidade, transporta em sua mala (ou na sua mente) as histórias dos valentes vaqueiros para outras regiões do país, confirmando os estudos de Santos (2010) e corroborando o nosso pensamento. Assim, podemos entender que os elementos da vaquejada continuam sendo tema dos poetas de bancada nesse período que o Cordel também passa por transformações e conquista novos espaços para se reinventar enquanto tradição. Em Lenda do vaqueiro misterioso - folheto de oito páginas - Gonçalo Ferreira narra a lenda de um boi que jamais se deixou apanhar por alguém, "Porém um dia num belo / festival de apartação / apareceu um vaqueiro" (p. 3), que acabou dominando o boi, com o uso de algumas palavras, sem que ele esboçasse nenhuma reação. Mas o vaqueiro não pôde receber nem a glória nem o dinheiro (ofertado para quem o pegasse) até que provasse ser um verdadeiro vaqueiro; e com outras palavras ele fez o boi disparar no matagal, partindo atrás em seguida. Daí, após fazer aquilo que se espera de um vaqueiro, "Mostrando o boi ao patrão", devolvendo-o ao curral, foi louvado como tal, "E misteriosamente / da forma que apareceu / como quem reflete algo / que a muito aconteceu / fitou o céu por instante / depois desapareceu" (p. 8), deixando a impressão de que enquanto existir um barbatão, sempre aparecerá um "herói” (vaqueiro) para enfrentá-lo e vencer, independentemente do tempo e do espaço. Vê-se neste Cordel a história de um vaqueiro misterioso (sobrenatural) que enfrenta um boi lendário típico das tradições sertanejas, sem nada de coisas de outro mundo.

Já o poeta cordelista Antônio Klévisson Viana, grande expoente da cultura "popular" da atualidade, além de ser produtor e editor, é um grande divulgador do Cordel brasileiro, pois tanto difunde as suas obras quanto as de outros poetas, através da editora Tupynanquim, da 
qual é o proprietário (tupynanquimeditora.blogspot.com.br). Daí a sua importância para a nossa pesquisa.

Nascido no sertão do Ceará - Quixeramobim - é notável a presença das tradições sertanejas em seus cordéis. Mas o que me chamou a atenção foi o folheto Sertão Menino (2013), no qual o poeta narra as memórias de sua infância no sertão cearense. É um texto de cunho memorialístico, produzido em décimas de sete sílabas, com oito folhas, que mostra a importância do vaqueiro e da vaquejada, e das transformações que enfrentam as tradições sertanejas nos dias atuais. Esta denúncia surge logo na primeira estrofe e é corroborada na última, demonstrando que este tema não foge da memória e nem das escritas dos cordéis após mais de cem anos, como podemos ler na íntegra nestas duas estrofes.

\author{
Menino, lá no sertão \\ Me banhava no riacho \\ E brincava de vaqueiro \\ Pra provar que era macho \\ No meu possante cavalo \\ Que era feito de talo \\ De carnaúba, seu moço! \\ Inda tinha uma boiada \\ Que era muito afamada \\ Toda de gado de osso... (p. 1). \\ $[\ldots]$ \\ Saudade, muita saudade \\ Do sertão puro e decente... \\ Que o tempo modificou \\ E fez ficar diferente; \\ Ah, se eu pudesse encontrar \\ Uma forma de voltar \\ Ao meu sertão do passado... \\ Voltava, nesse momento, \\ Num cavalo pensamento \\ Pra correr atrás do gado (p.8).
}

Fazendo uma análise mais detalhada, nesta obra, veremos a valorização da vaquejada de uma forma que podemos afirmar ser uma das tradições mais marcantes da cultura sertaneja. E mais, vemos também as preocupações do poeta quanto às mudanças ocorridas através do tempo, assim como percebia Cascudo (1984) no início do século XX. Pelo menos no Cordel parece não mais existir esta tradição infantil que instigava à prática da vaquejada, mas fica evidente a tradição de se fazer poesia, principalmente em Cordel, enaltecendo sua importância como patrimônio cultural de um povo.

Todas estas informações fortalecem a ideia de que Cordel e vaquejada se reinventam e se reconstroem através do tempo, se adequando às necessidades impostas pelo contexto histórico. Esta é uma pesquisa que ainda tem muito a se expandir, pois sabemos que hoje o 
Cordel também já é explorado como instrumento de defesa dos animais e, consequentemente, como elemento de divulgação dos que defendem o fim da vaquejada nordestina. Mas esta não é a nossa linha de pesquisa (no momento) e, portanto, não faz sentido nos estendermos nessa direção.

\section{A vaquejada como tema na consolidação do Cordel nordestino}

Fazendo uma pesquisa nas obras destes quatro poetas, indicados por Aderaldo Luciano como os responsáveis pela consolidação do Cordel brasileiro, pude constatar em suas histórias a forte presença destes três elementos - o boi, o cavalo e o vaqueiro - indispensáveis à prática da vaquejada. Aliás, durante a pesquisa não detectamos a presença de elementos da vaquejada nas obras de Silvino Pirauá (1848-1913), talvez porque existam poucas obras disponíveis nos acervos onde pesquisamos, não sendo possível comprovar a relação do poeta com os vaqueiros através da sua produção de folhetos.

Para tanto, buscamos a presença da vaquejada de forma direta ou indireta nas obras destes poetas nos arquivos do Memorial do Cordel José Camelo de Melo Resende, localizado na cidade de Guarabira, na Paraíba; na cordelteca online da Fundação Casa de Rui Barbosa (FCRB), considerada um dos maiores acervos virtuais do Brasil neste gênero literário; e em algumas antologias de Cordel apresentadas na bibliografia deste artigo.

Nos acervos pesquisados encontramos algumas obras de Francisco das Chagas Batista (1882 - 1930) que tratam deste tema de alguma maneira. Identificamos no folheto Antonio Silvino: vida, crimes e julgamento - folheto de 32 páginas - a figura do vaqueiro de uma forma enaltecedora. Nele, o poeta se oculta e a narrativa se desenvolve na primeira pessoa, fazendo com que Antonio Silvino mostre sua trajetória de vida, afirmando que é originário de uma terra onde: “Ali se aprecia muito / Um cantador, um vaqueiro / Um amansador de potro / Que seja bem catingueiro / Um homem que mata onça / Ou então um cangaceiro" (BATISTA, 2016, $6^{\text {a }}$ estrofe). Subentende-se, com esta estrofe, que a figura do vaqueiro está no mesmo patamar dos "herois" sertanejos da época - cantador, amansador de potro, matador de onça, cangaceiro - na visão do poeta. Igualando-se, neste aspecto, vaqueiro e cantador, mesmo que o assunto central do folheto seja a vida do cangaceiro Antonio Silvino.

A presença da figura do vaqueiro nas obras de João Martins de Ataíde (1880 - 1959) é constante e valoriza muito bem a vaquejada nordestina, e o trabalho de restituição de autoria realizado por Batista (1973), além de mostrar os verdadeiros criadores das histórias, deixa evidente a importância de João Martins de Ataíde no sentido de propagar o personagem do 
vaqueiro por meio dos folhetos, levando em consideração que o mesmo foi e é considerado como um dos grandes autores e editores de Cordel.

JOÃO MARTINS DE ATAÍDE [...] Tornou-se famoso autor e editor de folhetos, depois de ter comprado os direitos autorais do grande poeta popular Leandro Gomes de Barros, 1921 [...] Adquirindo originais de outros poetas populares publicava-os, fazendo constar apenas o seu nome como Editor Proprietário, a fim de preservar sua propriedade literária, razão por que é atualmente muito difícil saber com precisão quais os folhetos de sua autoria (BATISTA, 1977, p. 141).

Desta forma, considerando-se as restituições de autoria, pudemos encontrar (em seu nome) algumas obras em que o vaqueiro é tratado com exaltação, como, por exemplo, em $A$ história do boi misterioso, Suspiros de um sertanejo e Testamento e vida de Cancão de Fogo (atribuídas a Leandro Gomes de Barros); Interrogatório de Antonio Silvino na prisão (atribuída a Francisco das Chagas Batista); A História do Boi Mandingueiro e o Cavalo Misterioso; O casamento de Chico Tingole e Maria Fumaça... Enfim, Ataíde pode não ter sido um grande versejador das festas de vaquejada/apartações, ou dos feitos dos vaqueiros, mas não se tem dúvidas de que foi um grande divulgador da Literatura de Cordel até o final da década de 1949.

Encerrando o ciclo de pesquisa em torno dos quatro nomes da poesia "popular" mencionados por Luciano (2012) como os responsáveis pela consolidação desta literatura em nossa sociedade, fomos buscar as obras de Leandro Gomes de Barros para saber as quais abordam o assunto e como é que o "pai do Cordel" faz referência à vaquejada, se de forma direta ou indireta; tendo em vista que muitas histórias não têm como tema central a apartação/vaquejada e o boi e nem o vaqueiro em si, mas a prática e os vaqueiros são introduzidos no enredo como símbolo heróico da cultura sertaneja, como ficou perceptível nas obras de Francisco das Chagas Batista e João Martins de Ataíde, por exemplo.

Muitas narrativas de Leandro abordam os principais elementos da vaquejada no seu enredo. Duas delas estão relacionadas ao cangaço, especificamente ao Antonio Silvino, assim como fez Chagas Batista, demonstrando o valor do vaqueiro no cenário sertanejo nordestino. Antonio Silvino no Jury - folheto de 16 páginas - é uma história contada por Leandro, na qual o poeta dá voz ao personagem, e este após o seu julgamento e se encontrando na prisão começa a relembrar o passado e as coisas boas/belas que vivera outrora, deixando transparecer o seu lado nostálgico ao narrar: "A liberdade do povo / Os encantos do sertão / Os cantos dos passarinhos / Um tempo de apartação / O homem que não chorar / Nunca teve coração" (p.12). É claro que esta é uma versão romântica da vida do cangaceiro representada 
pelo cordelista. E em meio a essas belas lembranças surge a festa de apartação como algo bom e digno de ser relembrado, mostrando que as festas organizadas em torno das fazendas que deram origem às vaquejadas irão fazer falta neste seu novo modelo de vida, agora na prisão. Seria, de fato, o lado nostálgico do cangaceiro sob a percepção do poeta enfatizando as raízes da vaquejada.

A vida de Antonio Silvino é um tema bastante narrado por Leandro e nele é constante a inclusão do vaqueiro para ilustrar a bravura e o valor do povo sertanejo. Em Antonio Silvino o rei dos cangaceiros - folheto de 16 páginas - mais uma vez o poeta narra o texto na primeira pessoa, deixando que o próprio Antonio Silvino conte a sua vida, suas revoltas, suas proezas, seus pensamentos. Ao narrar algumas dificuldades da vida, o personagem acaba deixando um conselho aos que pretendem se arriscar naquela 'terrível' vida, utilizando o exemplo de um boi perseguido pelo vaqueiro como exemplo de desgraça da vida do boi, ou da vida do sujeito. Ou seja, o personagem (na visão do poeta) afirma que o sujeito para ser um cangaceiro não pode nada temer e se "Não podendo fazer isso / Nem pense em ser cangaceiro, / Que é como um Cavallo magro / Quando cáe no atoleiro, / Ou um boi estropiado / Perseguido do vaqueiro". (BARROS, p. 14). Vê-se nesta estrofe que a perseguição do vaqueiro é a desgraça do boi, deduzindo-se que quanto mais lendário for o animal mais glorioso será o vaqueiro, não sendo diferente das perseguições empreendidas nas apartações ou nas atuais vaquejadas.

Como é constatado, Leandro produziu muitas histórias com temas bastante variados, contendo humor, sátira, denúncia, crítica social, romances. Mas, como afirmamos anteriormente, é possível ver a figura do vaqueiro em várias situações criadas pelo poeta, quase sempre para engrandecer o discurso acerca da população sertaneja. Em A vida de Pedro Sem e sua chegada ao céu, Leandro narra a vida de um personagem muito rico e avarento que viveu há bastante tempo no reino de Portugal. Nesta história fantástica, o autor faz o trocadilho com os termos "cem" e "sem" para mostrar o princípio e o fim da vida de Pedro. Ela não teria nada a ver com o tema que estamos trabalhando nesta pesquisa, tendo em vista que ela faz menções a uma viagem (puramente ficcional) ao céu, a não ser pelo fato de que o autor utiliza as fazendas de gado e o vaqueiro como um dos símbolos da riqueza de Pedro Cem. Resguardando o imaginário criativo do poeta, vemos que, ao relatar os bens possuídos pelo personagem, ele faz uso de elementos que condizem com a riqueza sertaneja. Ou seja, é a realidade cotidiana do poeta se entrelaçando na ficção da vida do personagem. Em síntese, nesta narrativa, as fazendas de gado e os vaqueiros aparecem como símbolo de riqueza de Pedro Cem, sendo exposto quando Leandro Gomes de Barros afirma que ele tem entre tantas outras coisas: "Cem mil fabricos de vinho, / Cem mil fazendas de gado, / Cem mil vaqueiros 
no campo, / Cem mil homens no roçado; / Cem fabricos de manteiga / E de queijo apreciado". (BARROS, s/d, p.4). Ter muito gado implica ter muitos vaqueiros; e ter muito gado e grandes fazendas na época vivida pelo poeta significava ter festas de apartação; que Cascudo (1984) alega terem sido animadas por poetas cantadores.

Outro Cordel que representa muito bem a cultura nordestina, escrita por Leandro, é Suspiros de um sertanejo - folheto de 16 páginas - incluindo o vaqueiro e a vaquejada de forma admirável, deixando transparecer que estes elementos são símbolos marcantes da identidade de um povo. Neste poema, o autor "brinca" com a arte de fazer Cordel, dialogando com o romantismo do viver sertanejo e com as modalidades estruturais do gênero. O texto é escrito em sextilhas de sete sílabas (redondilha maior) e em décimas de cinco sílabas (redondilha menor), alternadamente, criando uma beleza poética imensurável. O poeta, como um bom sertanejo, após descrever as belezas e tradições de sua terra encerra o poema alertando para o sentido principal da poesia.

\author{
Leitores, ia me esquecendo \\ De tratar na criação, \\ Não só matava a história, \\ Como atrasava a ação \\ Visto o começo da obra \\ Ser dirigida ao sertão. \\ Com todo o cuidado. \\ Diz o fazendeiro: \\ -Eu mando o vaqueiro \\ Ajuntar o gado! \\ E ele, vexado, \\ Faz-se logo ao val. \\ Pelo matagal \\ Segue a vaqueirama \\ Aboiando chama \\ O gado ao curral. \\ É belo ver-se no campo \\ Os vaqueiros encourados \\ Tangendo um aboio saudoso, \\ Dando a conhecer os gados \\ Que comparecem às revistas, \\ Como que sejam soldados.
}

\title{
$[\ldots]$
}

Em revista que eu trato

Chama-se apartação

Uma das maiores festas,

Mais faladas do sertão,

Nem um carnaval de praça

Tem tanta apreciação.

Quem no mês de abril

Por ali viajou, 
Diz que já passou

Por belezas mil -

Viu um céu de anil,

Um campo de ouro,

Viu um grande touro

Vir dos matagais,

O vaqueiro atrás

Com vestes de couro.

Então naquela fazenda

Que o gado há de se juntar,

Há uma festa soberba,

Tem muito que apreciar -

$\mathrm{O}$ resto daquele ano

Inda se ouve falar.

É na apartação,

Que vê-se os valores

Dos vaquejadores

Que há no sertão.

Quando um barbatão

Espirra ligeiro,

Grita-lhe o vaqueiro:

-Trate de correr!

Havemos de ver

Quem cansa primeiro.

O cavalo que já é

Costumado a vaquejar

Se aproxima do boi,

Para o vaqueiro pegar;

De fora, a gente só vê

É o mocotó passar.

É belo ver a chegada

Do gado para o curral:

Os vaqueiros encourados

Tirando o gado do val,

Com cuidado que os novilhos

Não entrem no mufumbal.

O touro, se vê,

No sol muito quente -

Vaqueiro na frente

Não deixa correr.

Pega a arremeter,

Fazendo explosão;

Fazendo menção,

Espirra ligeiro,

Porém o vaqueiro

Estende-se no chão!

(BARROS, apud MEDEIROS, 2002, p.253-4).

Tudo o que Cascudo (1984) afirma acerca das festas de apartação, suas finalidades específicas, Leandro descreve rimando no poema, Suspiros de um sertanejo. Quanto a isso não temos dúvidas de que os poetas e vaqueiros têm uma história correlativa. Mas, não fugindo das nossas expectativas, A história do boi misterioso foi e continua sendo o grande 
Cordel que retrata a figura do vaqueiro de maneira grandiosa, tendo sido escrito e publicado por Leandro no ano de 1912, e reeditado por diversos poetas e editores de folhetos até os dias atuais. E mais, esta história é uma das tantas de Leandro que sempre se fazem presentes nas inúmeras antologias de Literatura de Cordel publicadas no Brasil. Por esse motivo é que iremos fazer uma análise mais detalhada desta obra, buscando identificar a figura do vaqueiro e a representação da vaquejada em seus versos. Iremos ver o que ela tem de especial para nossos estudos, até mesmo porque sabemos que se trata de uma história fantástica, totalmente ficcional; e como defende Luciano (2012), ela imortalizou a presença do boi no Cordel brasileiro.

\section{A representação da vaquejada n'A história do boi misterioso}

A história do boi misterioso tem o seu reconhecimento entre os apreciadores da Literatura de Cordel tanto pelo seu enredo quanto pela sua estrutura poética. É uma história um tanto fabulosa, sobrenatural e mágica que consegue conquistar o leitor pelas possibilidades de ser reinterpretada. Todo construído em sextilhas com versos de sete sílabas poéticas, o texto dialoga com a ficção, com o imaginário popular, e também com a realidade sertaneja, inferindo-se que muitas pessoas no interior nordestino foram alfabetizadas (CAMPOS, 1959) com as lendárias aventuras que envolvem o boi misterioso e os vaqueiros sertanejos, na dialética, leitores e ouvintes.

Como vimos nas obras de Francisco das Chagas Batista e João Martins de Ataíde, o vaqueiro e a vaquejada não são temas centrais das narrativas. Eles apenas aparecem como elementos idealizados para enriquecer a história, fazendo com que o leitor se perceba na história (TODOROV, 2009, p.23), reconheçam o seu mundo até mesmo em meio às viagens utópicas, como por exemplo, a chegada de Pedro Cem ao céu. Os elementos da vaquejada surgem nos textos como exemplo de riqueza, como símbolo heróico ao lado do cangaço e cangaceiro, como lembranças de coisas boas que ficaram no passado. Enfim, mesmo ocupando lugar periférico nas aventuras dos poetas cordelistas, eles servem para ilustrar muito bem a identidade de um povo.

Neste sentido, A história do boi misterioso não se distancia dos demais cordéis discutidos até aqui, isto porque o personagem central da obra é o boi, sendo que os demais participantes atuam sempre em função das qualidades do animal.

Cascudo, em seu livro, Vaqueiros e Cantadores, destaca que era bastante comum a exaltação do boi por parte dos cantadores da época. E para explicar estas práticas, o 
pesquisador descreve a história de um cantador do Rio Grande do Norte, de nome Fabião das Queimadas, afirmando que: "Em vez de deter-se em narrar a vaquejada, o velho Fabião apaixonou-se por um novilho cabano (de orelhas pendentes) que não foi alcançado pelos vaqueiros" (CASCUDO, 1984, p. 110). Ou seja, um animal arredio e valente que não se deixa vencer pelos vaqueiros é um instrumento de orgulho para os poetas, bem como para os admiradores da derrubada do boi.

Parece um pouco estranho dizer que os bois lendários, aqueles que nunca são apanhados pelos vaqueiros, são dignos de orgulho dos apreciadores da vaquejada, mas a explicação parece simples e plausível. São estes animais que aumentam a glória de seus possíveis derrubadores, pois o vaqueiro é aquele que não desistia de reunir o gado em tempo de apartação, que não desistia e não desiste de perseguir os mais lendários bois mandingueiros, nem mesmo aqueles mais famosos que surgem no imaginário como sobrenaturais, como mal assombrados, como verdadeiras lendas.

Leandro Gomes de Barros não fez diferente ao criar A história do boi misterioso, colocou todos os ingredientes idealizados para uma boa corrida de apartação à disposição dos seus leitores. Sabemos que o enredo da obra é totalmente ficcional, repito, mas também sabemos que as práticas desdobradas pelos vaqueiros nesta ficção não se distanciam muito (ou quase nada) dos conhecimentos expostos nos estudos historiográficos produzidos nas academias sobre o tema.

Como faz a maioria dos poetas de bancada, nas primeiras estrofes é feita uma introdução à obra, descrevendo os personagens, o cenário e uma possível conclusão, e assim fez Barros (2002): descreveu o personagem central nas duas primeiras linhas e a princípio já foi alertando para as suas glórias, sem deixar de mencionar os três elementos indispensáveis à prática do esporte: "Durou vinte e quatro anos / Nunca ninguém o pegou, / Vaqueiro que tinha fama / Foi atrás dele e chocou / Cavalo bom e bonito / Foi lá porém estancou" (p.46). Com esta apresentação, imagina-se que este boi fez a festa dos vaqueiros por mais de duas décadas, considerando-se que os vaqueiros não desistem antes de pegá-lo e recolher aos currais da fazenda (tomando como regra a festa de apartação), mas que a festa não acabou e nem acabará enquanto o boi existir.

Com o tom apologético, o poeta continua a descrever sua história. Aliás, o animal parece mesmo ser bastante assustador, pois "Acaso enganchasse um chifre / Num galho de catingueira / Conforme fosse a vergôntea / Arrancava-se a touceira" (Idem), deixando claro o perigo enfrentado pelos vaqueiros que o perseguissem. Além da força física do boi, os fracassos dos vaqueiros são apresentados nesta narrativa, pelo fato de que, "Como nunca 
achou vaqueiro / Que em sua cauda pegasse" (Idem), este animal representa aquilo mostrado por Cascudo quando afirma que os vaqueiros após a corrida do gado se reuniam para narrar façanhas e revelar “derrotas alheias” (CASCUDO, 1984, p. 107). Está denunciada, portanto, a derrota alheia dos vaqueiros persistente há vinte e quatro anos.

A origem do boi é bem fantasiosa, filho de uma vaca também misteriosa, tida como feiticeira, ou espécie de lobisomem, que parece não ter nada de real. Ou melhor, pode não ser comparada com a realidade social sertaneja até o momento em que se inicia a perseguição do fantasmagórico boi, pois a partir de então surge um cenário bastante difundido pelos estudiosos regionalistas da área; e mais, não se pode desprezar a idéia de que as lendas fazem parte do cotidiano dos sertanejos nordestinos, e, assim sendo, a história habita a realidade dos leitores e admiradores tanto da vaquejada quanto do Cordel.

Voltando à análise do texto, vê-se que o surgimento do boi é motivo de alvoroço entre os habitantes da redondeza - "No sertão de Quixelou / Na fazenda Santa Rosa/ No ano de vinte e cinco [...]" (Idem) - e a notícia se espalha rapidamente entre os vaqueiros ao ponto de se reunirem em busca da captura do animal, como diz o poeta: "Foi Norberto da Palmeira / Ismael do Riachão, / Calixto do Pé da Serra, / Félix da Demarcação, / Benvenuto do Desterro, Zé Preto do Boqueirão" (p. 48). Esta estrofe seria apenas uma coincidência ou estaria relatando as informações do grande pesquisador e folclorista Cascudo (1984) a respeito das pessoas que ganhavam outros nomes por algum aspecto característico? Relatando as suas memórias e as suas preocupações acerca das tradições que iam se (des)construindo com o tempo, Cascudo fez menção a costumes arraigados nos sertão que remetiam aos tempos feudais, (expondo o poder das tradições) afirmando que viveu nas terras onde "Todos eram conhecidos pelo nome próprio acrescido do topônimo. Coronel Zé Brás dos Inhaumas, Chico Pedro da Serra Branca, Manoel Bazio do Arvoredo" (CASCUDO, 1984, p. 16-7). Parece plausível ser uma tradição também entre os vaqueiros essas alcunhas. Isto demonstra nitidamente que, na poesia, os costumes se misturam, assim como os vaqueiros se reúnem para poder vencer o boi lendário.

Outro sinal do cotidiano sertanejo denunciado no Cordel é a tradição de se marcar o gado para facilitar no momento da identificação, tendo em vista que a principal finalidade das apartações alegadas por Cascudo é a devolução dos animais aos seus legítimos donos. Ou seja, mesmo o boi misterioso tendo desaparecido da fazenda sem nenhuma marca foi possível identificar o dono do animal, “- Pois tem na orelha esquerda / Três mossas mais um canzil, / Tem na orelha direita / Brinco lascado e funil / O ferro da Santa Rosa, / Está nele a marca buril" (CASCUDO, 1984, p. 49). 
Pressupõe-se que os bons vaqueiros correm léguas atrás dos bois indomáveis e como já foi dito (neste texto) e confirmado pelo poeta, eles se reúnem onde existir um boi de difícil captura, subtendendo-se que a glória destes sujeitos enaltecida pelos poetas e cantadores faz jus às suas ações. Neste aspecto, apresenta-se nesta história um daqueles enaltecidos nas conversas e cantorias assinaladas por Cascudo nos jantares das apartações. Ele vem das Minas Gerais para pegar o boi e dar prosseguimento a sua fama de bom vaqueiro. Ficando perceptível quando o coronel da fazenda Santa Rosa, dono do boi misterioso, oferece uma razoável quantia em dinheiro para aquele que o pegar, e "Disse o moço: - Não aceito / Objetos em dinheiro, / Eu só desejo ganhar / A vitória do vaqueiro; / Este seu menor criado / É filho de um fazendeiro" (p. 52). Todas estas informações significam dizer que os valentes e aguerridos vaqueiros não eram apenas pessoas necessitadas financeiramente, eram pessoas de posses e que enfrentavam aquelas situações pelo prazer de serem reconhecidos como vaqueiros herois, verdadeiros símbolos de identidade para o povo sertanejo, e nordestino de uma forma geral. Talvez isto explique aquela preocupação de Cascudo (1984) em relação às transformações que sofria o sertão do início do século XX, quando os filhos dos fazendeiros se dirigiam às capitais em busca de estudos, ou quando os próprios fazendeiros se debandavam para o litoral, só voltando no período da safra de algodão, ou ainda quando as estradas e o automóvel tornavam as distâncias mais curtas e com elas desapareciam algumas tradições. Enfim, Cascudo parecia denunciar o perigo de extinção que corria a vaquejada, sendo por falta de sujeitos como este vaqueiro das Minas Gerais apresentado no Cordel, ou por causa das modernidades introduzidas no campo, como ele bem explica:

\footnotetext{
Não há "apartação" sem vaquejada mas são atos diversos. Vaquejar, na acepção legítima, é apenas procurar o gado para levá-lo ao curral. Hoje a apartação rareia. Todo sertão está sendo cercado. A pecuária possui métodos modernos. Já apareceram veterinários. A maioria do gado é "raceado". [...] Não sabem esses bois atender ao "aboio". Não são bons de puxar (CASCUDO, 1984, p.108-09 grifos do autor).
}

Tudo isto faz pensar que enquanto existir o boi, o cavalo e o vaqueiro, haverá vaquejada. Mesmo que o boi seja um fantasma igual ao boi misterioso do poeta (lendário e sobrenatural), certamente, aparecerá um vaqueiro também misterioso para segui-lo e dar continuidade às aventuras. Na vida real sempre haverá um boi a ser derrubado por um vaqueiro, bastando que a tradição se adeque às imposições da modernidade, reinventando-se e se adaptando ao meio.

Portanto, cada estrofe, cada verso, cada palavra escrita por Leandro Gomes de Barros n'A história do boi misterioso pode ser analisada como parte do cotidiano da vida do 
vaqueiro, ou melhor, o Cordel brasileiro pode ser considerado como um excelente instrumento de divulgação das tradições nordestinas, levando informação de forma agradável e prazerosa, assim como deve ser qualquer prática de leitura.

\section{Considerações finais}

Chegamos ao fim deste texto com a certeza de que Cordel e vaquejada se reconstroem através do tempo na luta pela sobrevivência enquanto tradições. Também temos a certeza de que o Cordel foi um grande instrumento de divulgação deste esporte, e apoderando-se da sua riqueza cultural e do seu público admirador conquistou novos espaços, novos públicos, novos formatos, novas pretensões.

Quando se analisa a trajetória do Cordel brasileiro é possível compreender o seu valor para o processo educacional do país. Fica clara a sua função social perante os leitores e ouvintes. Como fica evidente neste artigo, pois os cordéis só passaram a ser objetos de estudos das academias brasileiras por volta da década de 1960 - 1970, mas mesmo assim não se pode negar a sua importância para o processo de alfabetização das pessoas das áreas mais afastadas dos grandes centros urbanos (CAMPOS, 1959), não esquecendo que estes eram lidos pelos vendedores e ouvidos por grandes aglomerações de pessoas, nas feiras livres, festas populares e no seio das famílias nordestinas.

Com sua introdução nas universidades como objetos de estudos, viu-se também o seu valor como instrumento pedagógico no ensino básico. Sem ser esquecido que foi neste contexto histórico que o Cordel se difundiu pelo Brasil, viajando na mala dos migrantes nordestinos (SANTOS, 2010).

Quando se acreditava que o Cordel iria perder as forças, eis que ele se atualiza em meio às transformações tecnológicas e sociais deste mundo globalizado. Ou melhor, ele se adequa ao meio, mas continua levando consigo a representação da vaquejada para outros espaços, como evidenciamos até aqui. E mais, são inimagináveis os lugares visitados pelo boi misterioso (com as suas fantasias e realidades cotidianas) neste vôo conduzido pela Literatura de Cordel, levando-se em conta as reproduções desta obra espalhada pelo mundo. E não desprezando o pensamento de que a literatura na sua forma mais ficcional serve para formar leitores, formar pensadores, formas cidadão reconhecedores de si e do outro (TODOROV, 2009).

Neste aspecto, as considerações finais devem, também, ficar por conta dos leitores. Especialmente por aqueles que admiram a história cultural e se reconhecem neste discurso 
sobre estas duas culturas, que ao meu entender, simbolizam muito bem a identidade de um povo - sertanejo nordestino e brasileiro.

\section{Referências}

ALMEIDA, Elga Helena de Paula. Maus tratos contra animais. 2011, 64p. Monografia (Graduação em Direito) Universidade Presidente Antônio Carlos - UNIPAC - Barbacena, 2011.

AMARO, Alexandra; FELGUEIRAS, Margarida Louro; LENCASTRE, Marina Prieto. “A educação e o movimento de defesa dos animais não humanos em Portugal na transição do século XIX para o Século XX”. EXEDRA Revista Científica ESEC. Coimbra: 2013, p. 2939. Disponível em: http://www.exedra journal.com/wp-content/uploads/2014/09/031.pdf Pesquisado em: 14 de julho de 2016.

BARROS, Leandro Gomes de. Antonio Silvino no Jury. Debate de seu advogado. s/d. Disponível em:

http://docvirt.com/docreader.net/docreader.aspx ?bib=RuiCordel\&pasta=\&pesq=Discucao $\% 20$ do\%20vinho\%20com\%20a\%20Aguardente Acesso em: 21 de julho de 2016.

Antonio Silvino o rei dos cangaceiros. S/d. Disponível em: http: //docvirt.com/ docreader.net/docreader.aspx ?bib=RuiCordel\&pasta=\&pesq=LC7057 Acesso em: 02 de agosto de 2016.

A vida de Pedro Sem e sua chegada ao céu. São Paulo: Prelúdio, s/d. Disponível em: http://docvirt.com/docreader.net/docreader.aspx?bib=RuiCordel\&pasta=\&pesq=LC7057 Acesso em: 22 de julho de 2016.

Suspiros de um Sertanejo. In.: MEDEIROS, Irani. No Reino da Poesia Sertaneja. João Pessoa: Idéia, 2002.

BATISTA, Sebastião Nunes. Antologia da Literatura de Cordel. Natal: Fundação José Augusto, 1977.

Restituição de autoria de folhetos do Catálogo, Tomo I, da Literatura Popular em Verso. In.: Literatura Popular em Verso. Rio de Janeiro: Fundação Casa de Rui Barbosa, 1973.

BATISTA, Francisco das Chagas. Antonio Silvino: vida, crimes e julgamento. São Paulo: Luzeiro, 1975. Disponível em: http://docvirt.no-ip.com/docreader.

net/DocReader.aspx ?bib=cordelfcrb2\&pagfis=391\&pesq= Acesso em: 31 de julho de 2016.

BLOCH, Marc. Apologia da história, ou, O ofício do historiador. Rio de Janeiro: Jorge Zahar, 2001.

BURKE, Peter. O que é história cultural? Rio de Janeiro: Zahar, 2008. 
CAMPOS, Renato carneiro. Ideologia dos poetas populares do Nordeste. Recife: Centro Regional de Pesquisa educacionais do Recife, MEC, INEP, 1959.

CASCUDO, Câmara. Vaqueiros e cantadores. Belo Horizonte: Ed. Itatiaia; São Paulo: Ed. USP, 1984.

A vaquejada nordestina e sua origem. Natal: Fundação José Augusto, 1971.

CHARTIER, Roger. A história cultural entre práticas e representações. Lisboa: DIFEL, 1990.

MARINHO, Ana Cristina; PINHEIRO, Hélder. O cordel no cotidiano escolar. São Paulo: Cortez, 2012. 